\title{
Mídias sociais e política: as jornadas de junho no facebook do PT
}

\author{
Social media and politics: the journeys june PT on facebook \\ Roberto Bitencourt da Silva ${ }^{l}$ \\ (betobitencourt@hotmail.com)
}

\section{Resumo}

O artigo tem como objeto de análise a página eletrônica do Partido dos Trabalhadores no Facebook. Guarda o propósito de identificar o comportamento, o perfil das abordagens e os significados atribuídos na webpágina - pelo partido e os seus usuários - às jornadas de junho de 2013. Visa ainda analisar o posicionamento do PT em relação à dimensão participativa da democracia, reivindicada pelas manifestações, assim como identificar determinados aspectos que caracterizam o ativismo digital dos usuários da página do PT no Facebook.

Palavras-chave: Ciberativismo. Partido dos Trabalhadores. Democracia.

\begin{abstract}
The article aims to analyse the website of the Workers Party on Facebook. It has the purpose of identifying the behavior, the profile of the approaches and the meanings assigned in the site - by the party and its users - throughout manifestations from June of 2013. This research also aims to analyse the position of the PT in relation to the dimension participatory democracy, as well as to identify some aspects that characterize the digital activism from users of PT Facebook page.
\end{abstract}

Keywords: Cyberactivism. Workers Party. Democracy.

\section{Introdução}

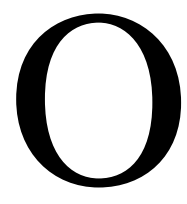

uso das mídias sociais com finalidades políticas tem suscitado a produção de um significativo número de estudos, que procuram identificar as características e as implicações inovadoras no comportamento coletivo. Malgrado a multiplicidade de enfoques e análises, não revelam expressão, ainda, trabalhos que se dediquem a observar a inserção dos partidos políticos nas webpáginas. Apesar de representar um dos principais agentes coletivos que protagonizam

\footnotetext{
${ }^{1}$ Doutor em História (UFF), mestre em Ciência Política (UFRJ) e professor da Faculdade de Educação Tecnológica do Estado do Rio de Janeiro (FAETERJ-Rio/FAETEC)
} 
a democracia contemporânea, carecem estudos sobre o perfil do comportamento dos partidos brasileiros nas mídias sociais, assim como dos usuários das suas páginas. Nesse preciso sentido, o artigo toma como objeto de análise a página eletrônica do Partido dos Trabalhadores no Facebook. Temos o propósito de identificar o perfil das abordagens e os significados atribuídos pelo partido e os seus usuários a um fenômeno político já considerado uma das maiores manifestações de massas da história republicana do país: as jornadas de junho de 2013.

Entendemos ser relevante submeter à análise o comportamento apresentado pelo PT - e na mídia social em foco, também a interação dos seus usuários -, por conta do saliente caráter apartidário da onda de protestos que se deu no mês de junho. Não raro, os protestos revelaram mesmo expressões antipartidárias. As jornadas de junho questionaram frontalmente a credibilidade das instituições representativas, particularmente dos partidos. Como o PT interpretou tal fenômeno? Como se comportou em relação às jornadas? Como os usuários da webpágina do partido no Facebook manifestaram-se e avaliaram as jornadas? Essas são algumas questões que o artigo pretende responder. Desse modo, o estudo propõe analisar o perfil da inserção do partido em uma relevante mídia social e o padrão de comportamento apresentado pelo PT, no que compete à substantiva expressão de democracia participativa que denotou o fenômeno das jornadas.

\section{Partidos, política e mídias sociais}

Os partidos políticos, em maior ou menor grau, apresentam a tendência à centralização decisória interna, por conta das preocupações organizacionais com o exercício, a conquista e a preservação do poder (DUVERGER, 1970). Em regra, a motivação ideológica inicial do partido tende a perder força no curso do seu itinerário, pelos mesmos motivos. O pragmatismo e a flexibilidade aos tempos tende a ganhar primazia. O desapossamento de poder decisório dos representados/eleitores - sejam simpatizantes exteriores ao organismo partidário, sejam os seus militantes -, prevalece em face dos partidos e dos seus dirigentes. Ademais, os partidos canalizam e modelam a opinião política (DUVERGER, 1970). Desempenham uma atividade pedagógica, politicamente formativa, no seio da sociedade civil. Em perspectiva histórica, também essa dimensão, a qual podemos classificar como educativa, é relevante ser considerada nas atividades dos partidos (SILVA, 2011). Entretanto, não é

Comunicação \& Informação, v. 16, n. 2, p. 53-71, jul./dez. 2013 
demasiado argumentar que ela tem sido deslocada para o segundo plano, na arena política nacional dos últimos anos, pela prioridade concedida aos ganhos eleitorais e à ocupação de postos governamentais.

Considerável poder de autoria na construção da agenda pública fica ao encargo políticoinstitucional dos partidos: uma nuança importante da história da democracia representativa, que conta com os partidos como um dos seus pilares de funcionamento. Tradicionalmente, a cultura política ocidental associa a democracia à competição partidária e eleitoral, com as esperanças das maiorias depositadas nessas organizações políticas coletivas. Portanto, o que os partidos políticos têm feito com o poder, há tempos, na sociedade brasileira e alhures vem proporcionando severas críticas à sua atuação, assim como contestações até mesmo à sua validade nos dias de hoje, enquanto organismos de representação da vontade popular (FONSECA, 2011-2012). O habitual distanciamento entre a propaganda e o programa partidário em relação às efetivas iniciativas encetadas pelos partidos tem redundado em elevado descrédito junto à sociedade civil. Vem há anos promovendo uma paulatina erosão da legitimidade da democracia representativa, é claro, não apenas no Brasil.

Um fator oriundo da ambiência externa aos partidos também incide decisivamente para o enfraquecimento da sua credibilidade: trata-se da midiatização do poder (CASTRO, 2006). O modo como os meios massivos de comunicação abordam a seara política tende a revelar um profundo compromisso com a sua espetacularização. O tema da moralidade pública é explorado às náuseas pelo noticiário, contribuindo para a consolidação da imagem de instituições políticas empedernidamente corruptas (CASTELLS, 2009; LIMA, 2013). Além disso, o enfoque jornalístico tende a recair nas performances pessoais dos líderes, nas suas tricas cotidianas, esvaziando o debate público sobre as questões propriamente políticas. Logo, fica reforçado o poder partidário das lideranças, colaborando para a conversão dos partidos em meras máquinas eleitorais (LEFEBVRE, 2011).

Em meio a esse cenário - marcado por décadas de supressão dos direitos sociais, como também pela expansão das fronteiras do princípio da mercantilização, na esteira da hegemonia neoliberal -, no Brasil e em demais latitudes, novas modalidades de participação política têm sido exploradas pela cidadania. Sobretudo pelos jovens, com base no uso das plataformas técnicas digitais. Ganha espaço o ciberativismo: uma expressão do uso politizado da tecnologia, que revela a potencialidade de envolvimento político mais participativo e horizontalizado, em comparação ao modelo partidário de 
participação e representação política. Toret (2012, p.138) classifica a esse recente perfil de participação política cidadã como tecnopolítica, isto é, a "articulação entre uso estratégico das tecnologias de comunicação (para a ação) e organização coletiva". Gestar e proliferar a condição autoral de "prosumidores" - ou seja, sujeitos que "cumprem funções de produtores e consumidores" de ideias, informações e mensagens políticas (SLIMIVICH, 2012, p. 138), participando ativamente dos circuitos da informação e da intervenção política - consistem em frutos visíveis do ciberativismo.

O ideal da democracia participativa aparece no horizonte do ciberativismo, segundo Castells (2009, p. 451), em virtude do uso das redes digitais "como ágora global de deliberação, sem submeterse a nenhuma das formas de burocracia" - como os partidos - "que surgem dos mecanismos de delegação do poder". Com efeito, a gramática adotada pela jovem blogueira Lina Ben Mhenni, ativista da revolução tunisiana, pode ser considerada emblemática, no tocante à concepção democrática que tende a tipificar a percepção dos cidadãos, envolvidos com práticas políticas que operam com as técnicas digitais, em múltiplas latitudes do globo: ideal de uma democracia "sem chefes, em que todos participem na tomada de decisões" (MHENNI, 2011, p. 59).

Detentoras das características sublinhadas e de tantas outras que ultrapassam os limites do trabalho, surpreendentes manifestações globais de mobilização e de participação política têm proliferado, tais como: a Primavera Árabe, sobretudo as insurreições populares na Tunísia e no Egito (SILVA, 2012); nos Estados Unidos, o movimento Occupy; e, na Espanha, o \#15M organizado pelo movimento Democracia Real ;YA!. Uma temática que subjaz a esses diferentes e novos movimentos sociais ciberativistas é a crise da representação e da intermediação política das instituições consolidadas. Com isso, experimentamos um contexto histórico marcado por salientes críticas e desafios impostos pela cidadania aos regimes autoritários e à própria democracia representativa (DAIBERT \& FERREIRA, 2012, p. 93). O ideal rousseauniano do exercício da soberania popular, por meio da participação política sistemática, alcança um fôlego renovado, com práticas políticas que potencializam o horizonte de uma e-democracia. O ciberativismo - e o seu corolário, a democracia digital - guarda o virtuoso potencial de monitoramento do poder em virtude de um empoderamento político dos indivíduos e de recursos técnicos favoráveis às práticas da deliberação pública (CARREIRO, 2012, p.114). 
Por outro lado, não se pode deixar de destacar limitações e riscos latentes nesses movimentos sociais, horizontalizados, apoiados no uso sistemático das plataformas digitais e destituídos de vinculação partidária. Uma limitação, oportunamente ressaltada por Zizek (2012, p. 16), refere-se à necessidade de um programa construtivo de ação política, para além da debilitação das autoridades e das críticas à ordem social: "Não se apaixonar por si mesmos", pelas ações políticas igualitárias, "prazerosamente" auto-referenciadas, traduz o sarcástico e pertinente receio do autor. No que concerne propriamente a um risco, a possibilidade de comunicação direta, via webmídias, entre cidadãos e representantes pode incidir em reforço do notório personalismo político brasileiro. No extremo, em conformidade com a abordagem de Kang (2012), guarda a latente virtualidade de suscitar comportamentos políticos de sabor fascista, com o eventual desprezo pelas instituições políticas intermediárias. As virtudes e os riscos potenciais não deixaram de incidir nas jornadas brasileiras.

\section{A cidadania vai às ruas no Brasil}

Tomando como referência as experiências das cidades de São Paulo e do Rio de Janeiro, podemos sublinhar que a dinâmica das intensas manifestações de rua, ocorridas em junho de 2013, apresentou dois momentos distintos, assim como características singularmente diferentes: o primeiro marco temporal pode ser destacado entre os dias 06 e 16 de junho; o segundo desenrolou-se a partir do dia 17 de junho, revelando substantiva força e espraiamento por múltiplas cidades do país até o final do mês. O evento catalisador da onda de protestos consistiu na crítica ao aumento das tarifas de ônibus e à má qualidade dos transportes públicos, envolvendo principalmente a juventude estudantil. Esse foi o foco e a origem dos protestos que marcou a primeira onda das jornadas de junho. O viés apartidário mas, não antipartidário -, do Movimento Passe Livre, em São Paulo, e do Fórum de Lutas Contra o Aumento da Passagem, no Rio de Janeiro, foi preconizado em não poucas oportunidades durante o curso das manifestações. Mobilizando sistematicamente aos dispositivos técnicos digitais, as convocações feitas para a participação cidadã nos atos, por meio da internet, escaparam da percepção das instituições que, nas últimas décadas, têm protagonizado a democracia representativa brasileira, ou seja, a maioria absoluta dos partidos políticos e os meios massivos de comunicação.

Comunicação \& Informação, v. 16, n. 2, p. 53-71, jul./dez. 2013 
Inicialmente a mídia tradicional abordou as manifestações sob um enfoque nitidamente demeritório, classificando aos manifestantes como "vândalos". Na cena política institucional, o posicionamento não era muito diferente. Contudo, as cenas chocantes de selvageria repressiva das Polícias Militares contra os jovens, cenas sistematicamente veiculadas pelas grandes empresas de comunicação, tenderam a gestar uma ambiência de solidariedade por parte da população com os manifestantes. Adicionalmente, no dia 15/06, a presidente Dilma Roussef recebeu estridentes vaias no estádio nacional Mané Garrincha, em jogo da Seleção Brasileira de Futebol, na Copa das Confederações, em Brasília. A combinação dessas circunstâncias, associadas ao fato de que grossa parte dos manifestantes pertencia aos estratos sociais médios, suscitou uma inflexão na abordagem das grandes empresas de comunicação. Nesse preciso sentido, seguimos a avaliação oferecida por Secco (2013, p.74): “Acompanhando seu mercado, a direita midiática se viu forçada a apoiar os manifestantes - mas com sua própria pauta”. Apelando à temática da corrupção, exaltando o desfraldamento da bandeira nacional e denotando um enviesamento antipartidário, os maiores veículos de comunicação nacional contribuíram para a conversão dos protestos iniciais, que contavam com poucos milhares de manifestantes, em verdadeiros movimentos de massas. Centenas de milhares de manifestantes foram às ruas, entre os dias 17 e 22 de junho. Nessa segunda onda dos protestos o renitente grito "Sem partidos!" ecoava nas ruas. A presidente da República, os governadores, os prefeitos, os parlamentares, situados em distintas posições do espectro político-partidário, enfim, todo o sistema político era submetido a severos questionamentos. Em que pesem eventuais limitações políticas das jornadas, não é demasiado argumentar que elas traduziram uma "política dos cidadãos" pelo bem comum, tipificada por uma "subjetividade que não se esgota nos partidos políticos", conforme a perspectiva de Nogueira (2004). Elas revelaram expressivas ações cujo horizonte guarda relação com o ideal da democracia participativa.

\section{As jornadas de junho na página eletrônica do facebook: como o PT assimilou?}

O estudo de caso visa a identificar o perfil de assimilação das jornadas pelo PT. Como o partido se comportou em relação à onda de protestos de junho? Como a avaliou? Quais os significados 
atribuídos? Essas são algumas indagações centrais, que têm por mote observar o posicionamento do PT em relação à dimensão participativa da democracia, reivindicada pelas jornadas.

O recorte temporal explorado consiste no período de 01/06/2013 a 30/06/2013. O objeto de estudo consiste na página institucional do PT, mantida em uma mídia social que tem alcançado ampla difusão entre os usuários das webpáginas: o Facebook, que conta com cerca de 70 milhões de usuários no Brasil. ${ }^{2}$ A análise mobiliza como fontes de investigação as postagens (notícias, textos, vídeos, imagens) veiculadas pelo emissor das informações, isto é, o PT, assim como os comentários feitos pelos usuários da página. ${ }^{3} \mathrm{O}$ estudo da emissão das informações permite identificar, parcialmente, o posicionamento, as avaliações e os valores esposados pelo partido no tocante à expressão de exercício da democracia participativa revelada pelas jornadas de junho. Ademais, a reflexão sobre os comentários registrados pelos usuários, na página da mídia social, guarda um potencial de análise acerca da natureza da interlocução em vigor, entre os usuários e o partido. Isso propicia o mapeamento do perfil da recepção das mensagens, sob dois ângulos, quais sejam: primeiro. A relação de reciprocidade entre os usuários e o responsável pela página eletrônica. Essa nuança é relevante, no sentido em que permite identificar traços de compartilhamento de ideias e crenças, um imaginário político comungado pelo partido e os seus adeptos (FERREIRA, 1997). Segundo. A abertura a manifestações de crítica e a proposições engendradas pela recepção ativa do usuário. Seguramente um fenômeno que as mídias sociais, como Twitter e Facebook, põem em evidência. Na esteira dos estudos de Certeau (2009) e Chartier (1991), que abordam expressões culturais e de comunicação tradicionais, podemos argumentar que a relação emissor/receptor das mensagens implica em considerar a margem de liberdade criativa dos receptores. As eventuais intenções do produtor de bens simbólicos (ideias, valores, imagens, notícias etc.), não raro, podem deixar de atingir o sentido esperado, na exata medida em que os sujeitos da recepção "assimilam” a esses bens de acordo com as suas experiências peculiares de vida, as suas visões de mundo, processando-os com variável grau de inventividade. ${ }^{4}$

2 G1. Facebook no Brasil cresce para 67 milhões, diz executivo. 19/03/2013. Disponível em: <http://g1.globo.com/tecnologia/noticia/2013/03/facebook-no-brasil-cresce-para-67-milhoes-de-usuarios-diz-executivo.html>. Acesso em: 22 ago. 2013.

${ }^{3}$ A seleção do material publicado pela webmídia do PT no Facebook foi realizada no intervalo dos dias 06 a 08 de agosto de 2013.

${ }^{4}$ Importa, contudo, ponderar que o acento em tal capacidade inventiva não desconsidera as assimétricas relações de poder que caracterizam o fenômeno da recepção dos bens simbólicos.

Comunicação \& Informação, v. 16, n. 2, p. 53-71, jul./dez. 2013 
Quanto ao método explorado pela pesquisa, em boa medida, valemo-nos de recursos de análise quantitativa. Decerto, um método distante de uma capacidade explicativa integral sobre o fenômeno, pois a subjetividade permeia as fontes submetidas à análise, já que elas consistem significativamente em discursos. Entretanto, em função da miríade de discursos selecionados, um exercício de categorização e de quantificação desses discursos e comentários se fez necessário. ${ }^{5}$ A quantificação das incidências de temas e opiniões políticas, como recurso de análise, permite a oferta de um panorâmico quadro das ideias apresentadas pelo organismo partidário e por seus usuários, nesse singular instrumento de comunicação. Possibilita também vislumbrar certas nuanças que caracterizam os usos politizados das ferramentas técnicas digitais de comunicação.

Posto isso, cumpre tecer algumas rápidas observações sobre o perfil da página do PT, tomando por base informações fornecidas pela própria administração do Facebook na página do partido. ${ }^{6} \mathrm{O}$ PT possui um total de seguidores que alcança a casa aproximada de 38.000 usuários. Majoritariamente, os seus usuários encontram-se na faixa etária de 25 a 34 anos de idade e são residentes na cidade de São Paulo. A página é mantida pelo departamento de comunicação do partido e foi criada em 07/04/2011. Os dados estatísticos disponíveis favorecem a percepção de determinados aspectos elucidativos sobre o perfil organizacional e os circunstanciais apelos da webpágina junto ao público. Salta aos olhos o fato de que a página institucional do partido revela, sobremaneira, um baixo número potencial de seguidores. A legenda possui líderes de expressão que possuem números equivalentes - ou mesmo superiores -, em suas respectivas páginas pessoais aos do próprio partido que integram. Um fenômeno análogo ao verificado no Partido da Social Democracia Brasileira e no Partido Socialismo e Liberdade. ${ }^{7}$ Como a

\footnotetext{
${ }^{5}$ Assim como demais vestígios físicos do passado, próximo ou remoto, presentemente também a página eletrônica do Facebook impõe uma dificuldade técnica à análise: em um intervalo inferior a dois meses ao marco temporal de interesse, boa parte das publicações e informações cotidianas do passado, na página virtual (a "Linha do tempo", no dispositivo técnico digital do Facebook), tende a ficar inacessível ao usuário. Como alternativa, além da visualização da própria página na temporalidade de interesse do estudioso, também os ícones "Vídeos" e "Fotos" podem ser explorados, já que, habitualmente, nas páginas dos partidos políticos, constam como publicações associadas de imagem, vídeo e texto. Utilizando os aludidos recursos de verificação e seleção das fontes, encontramos um total de 48 publicações na página do PT no Facebook, entre 01/06/2013 e 30/06/2013. Desse universo de postagens, selecionamos 22, o que perfaz o recorte porcentual de 45,83\% de publicações analisadas, que não deixa, eventualmente, de impor limitações ao estudo.

${ }^{6}$ As informações podem ser obtidas com um clique no item "Opções 'Curtir"” na parte superior da página do partido. A respeito, as informações e os números que seguem foram verificados no acesso realizado em 08/08/2013 e a página institucional do PT encontra-se no endereço eletrônico que se segue: <https://www.facebook.com/pt.brasil?fref=ts>.

7 À guisa de comparação, o ex-presidente Lula detém mais de 330 mil seguidores em sua página pessoal. Disponível em: <https://www.facebook.com/Lula>. Quanto ao PSOL (<https://www.facebook.com/pages/PSOL-Partido-Socialismo-eLiberdade/139591896063648?fref=ts>), que apresenta pouco mais de 2.000 seguidores, este denota números muito inferiores à página do deputado estadual Marcelo Freixo (PSOL/RJ), que supera a casa dos 60.000 usuários no Facebook. Disponível em:
}

Comunicação \& Informação, v. 16, n. 2, p. 53-71, jul./dez. 2013 
cultura não deixa de moldar o uso da técnica (SIMONDON, 2007), os números tendem a refletir, no ambiente virtual, uma provável reprodução do consagrado personalismo político brasileiro, isto é, a nossa cultura política tende a privilegiar um esquema identitário maior junto aos líderes, secundarizando os organismos partidários.

O partido político submetido à análise revela uma peculiar característica: no intervalo de tempo selecionado, a sua página no Facebook demonstrou ser preponderantemente acompanhada por adeptos (simpatizantes e militantes, filiados ou não). São os usuários que comungam os valores, as perspectivas e as iniciativas do partido, que, via de regra, integram a sua comunidade virtual. Os dados identificados no conjunto das postagens veiculadas pela página do PT são ilustrativos. Somando os comentários favoráveis às publicações (notícias, imagens, textos e vídeos) aos registros da opção "Curtir" (ícone que se encontra abaixo de cada postagem em uma publicação no Facebook) - que denota uma espécie de concordância passiva com o conteúdo da mensagem veiculada pelo emissor -, encontramos um porcentual de interação favorável à comunicação do PT que atingia o elevado número de $96 \%$ de manifestações dos usuários. Importa também observar que a natureza da interação era tipificada por um nulo diálogo de "mão dupla" entre os responsáveis pela página e os usuários. Aqueles emitiam as publicações, mas não respondiam às observações feitas pelos usuários. Provavelmente, isso pode decorrer do fato de que a página é administrada pelo departamento de comunicação, uma seção partidária que não possui maior autonomia para travar diálogos livres com o público. A webmídia do PT, nesse sentido, configura-se como um instrumento verticalizado de comunicação perante o público. Posto isso, estritamente no tocante à emissão das notícias da página do PT, durante o período de 01/06 a 30/06/2013, se pode afirmar que três grandes categorias de mensagens foram privilegiadas, conforme se pode observar no Gráfico 1.

<https://www.facebook.com/mfreixo>. Enquanto a webmídia do PSDB possui um total de seguidores que alcança a casa aproximada de 26.000 usuários, o governador do estado de São Paulo, Geraldo Alckmin (PSDB), possui mais de 44.000 seguidores, cf. dados dis poníveis em: 〈https://www.facebook.com/Rede45?fref=ts> e <https://www.facebook.com/geraldoalckmin>. Os números das páginas pessoais das lideranças políticas foram obtidos em acesso realizado em 15/08/2013. As páginas eletrônicas de PSDB e PSOL foram acessadas em 08/08/2013. 
Gráfico 1 - PT: natureza das postagens (01/06/2013 a 30/06/2013), números percentuais

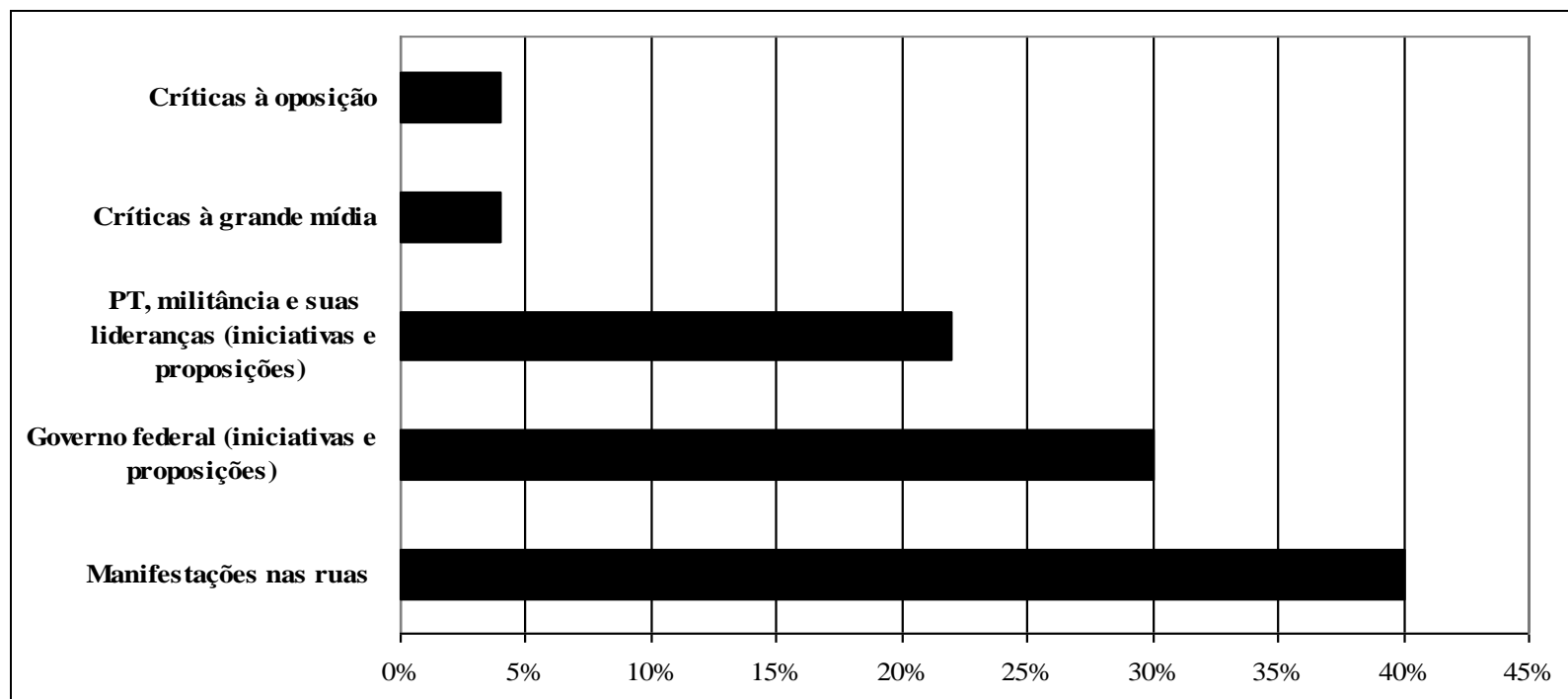

Fonte: Facebook

O recorte priorizado para o estudo é a abordagem sobre as manifestações de rua. Assim, incluímos na pesquisa a busca por menções críticas à grande mídia, nas postagens do partido, por corresponder a uma das mais marcantes questões que peculiarizou a voz e a ação das ruas na onda de protestos de junho. Sobre o assunto, encontramos apenas uma referência publicada pela página do PT, que não dizia respeito propriamente a um questionamento aos contornos institucionais e organizativos dos meios de comunicação. Tratava-se exclusivamente da veiculação de uma nota emitida pelo expresidente Luiz Inácio Lula da Silva (em 28/06/2013), contra "afirmações a ele atribuídas pela Folha de S.Paulo". Com efeito, um sinal plausível de posição confortável, ou acomodatícia, do partido em relação ao perfil da produção jornalística e cultural dos meios massivos de comunicação do país, em que pesem as críticas constantes recebidas por esses meios. Um posicionamento que destoava, ponderavelmente, de um importante tema reverberado por milhares de manifestantes nas jornadas de junho.

Grosso modo, três tipos de postagens ganharam substantivo espaço nas publicações petistas: $\mathrm{i}$. PT, militância e suas lideranças (iniciativas e proposições); ii. governo federal (iniciativas $e$ proposições); e iii. manifestações nas ruas. Sem a intenção de ultrapassar o escopo do trabalho, cumpre, 
contudo, frisar que, com $52 \%$ de incidências em suas postagens, as iniciativas encetadas pelo partido, por seus líderes e militantes, bem como pelo governo federal, conformaram a principal mensagem veiculada pelo PT no período. Com pouca atenção destinada a fazer críticas à oposição (apenas $4 \%$ das incidências) é possível afirmar que as mensagens petistas no Facebook tendiam a ser autoreferenciadas, importando potencialmente na criação de uma identidade partidária que se retroalimenta, secundarizando apelos a algum elemento antagônico ao partido. ${ }^{8}$ Para o que nos interessa em especial, se vê que as manifestações nas ruas conformaram $40 \%$ das mensagens noticiadas pela página petista no Facebook. O número foi significativo. Mais expressivo ainda foi o período em que as postagens foram feitas. Considerando um total de 10 (dez) publicações analisadas, cujo tema eram as manifestações, 9 (nove) foram feitas no intervalo dos dias 17/06 a 30/06/2013. ${ }^{9}$ Acompanhando a inflexão ocorrida nas abordagens das mídias comerciais, somente a partir do dia 17/06 o PT publicou notícias relativas às manifestações populares. Uma variável que implicava, de um lado, em um distanciamento do partido em relação às mobilizações levadas a cabo pelos manifestantes, na etapa inicial da onda de protestos. Nos primeiros dias das jornadas, o silêncio verificado na webmídia petista era acompanhado por declarações corrosivas, à imprensa, de alguns integrantes do PT, como o ministro da Justiça, José Eduardo Cardozo, e o prefeito paulistano, Fernando Haddad. Distanciamento inicial e adaptação posterior, em sintonia com a valorização empreendida pelas corporações midiáticas às manifestações, consubstanciaram o comportamento do partido em face das jornadas de junho. Apoiando-nos na perspectiva de Charaudeau (2009), não é exagero argumentar que se tratou de uma adaptação tardia da retórica partidária ao contexto social mais abrangente, ficando a reboque da pauta midiática. Por conseguinte, o PT demonstrou um precário manejo da sua dimensão pedagógica junto à sociedade civil.

\footnotetext{
${ }^{8}$ Conforme perspectiva de Stuart Hall, a identidade dos sujeitos, individuais ou coletivos, tende a ser construída por meio da diferença, do “outro". Na webmídia petista em foco não foi possível identificar a mobilização desse recurso antagônico pela retórica do partido. Talvez esse fenômeno possa ser atribuído à ampla gama de alianças políticas construídas pelo partido nos últimos anos, resultando em amortecimento de antagonismos, potencialmente levando ao PT à condição de um partido catch-all ("partido-ônibus", que carrega uma multiplicidade de atores, propostas e valores políticos), para usar uma expressão mobilizada por Scott Mainwaring. Consultar: HALL, S. A identidade cultural na pós-modernidade. 9. ed. Rio de Janeiro: DP\&A, p. 23-46, 2004. MAINWARING, S.P. Sistemas partidários em novas democracias. Rio de Janeiro: FGV, 2001.

${ }^{9}$ A única notícia veiculada antes do dia 17 de junho - e publicada em 14/06 - dizia respeito a uma manifestação favorável ao governador estadual do Acre, Tião Viana (PT). A informação não guardava qualquer relação com as jornadas.
} 
Tomando o dia 17/06 como ponto de inflexão na página do Facebook mantida pelo partido, vemos que a partir desse marco temporal as jornadas foram prestigiadas. Após dias de silêncio, em 17/06 a webmídia petista assinalava que a "luta pelo passe livre para estudantes no sistema de transportes públicos do país e contra aumentos de tarifas é histórica no país e sempre contou com ampla participação e apoio de petistas". No mesmo compasso, publicava nota da Comissão Executiva do PT do Estado de São Paulo, em que preconizava a participação da militância nas manifestações (também em 17/06). No dia seguinte, nova publicação veiculava o posicionamento do governo federal, por meio de pronunciamento do ministro-chefe da Secretaria Geral, Gilberto Carvalho, que argumentava que "a manifestação é própria da democracia e que o governo quer estabelecer um diálogo com os grupos que têm se manifestado nos últimos dias". Como recurso político oferecido ao atendimento parcial das demandas reverberadas pelas jornadas - após ter ventilado, em 24 de junho, o intento de estimular a criação de uma Assembleia Constituinte exclusiva para empreender a reforma política -, nos últimos dias do mês, a presidente Dilma Roussef (PT) afirmou o propósito de promover um plebiscito dedicado ao tema da reforma política. Na esteira do aludido intento, em 25 de junho, a página eletrônica noticiava que o partido "acredita na força do povo e quer que os brasileiros se envolvam na construção de uma nova história do nosso país!"’. Segundo o senador Humberto Costa (PT/PE), em postagem veiculada em 27/06, a proposta de reforma política tinha em vista "aprofundar a democracia no Brasil", de sorte a ampliar "a relação de transparência entre os eleitores e os eleitos". O plebiscito, um dispositivo da democracia participativa mobilizado pelo governo federal durante as jornadas, que mirava ao atendimento parcial dos reclamos populares pelo aperfeiçoamento das instituições políticas, foi questionado pelo PSDB. Na avaliação psdebista, publicada em sua página igualmente mantida no Facebook, em 25/06/2013, a proposta governamental do plebiscito expressava um "rascunho de golpe a la Chávez". Por contraste, a dimensão democrática da participação popular nos processos decisórios era problematizada pelo PSDB, revelando um esquema de percepção que acentuava a desejabilidade de preservação do modo empiricamente consolidado do regime democrático, isto é, assentado exclusivamente nas instituições representativas. Precisamente um dos cânones políticos mais questionados nas jornadas. Sob a luz desse ângulo, com a proposta plebiscitária, o PT parecia buscar a retomada de um componente político caro à sua trajetória organizacional, mas posto 
para escanteio nesses anos de exercício do poder no governo federal: o incremento da participação democrática.

No tocante à recepção das mensagens veiculadas pelo PT, como salientado, o perfil da interação foi tipificado por uma maioria esmagadora de usuários aderentes ao partido $(96 \%$ de incidências favoráveis às publicações da webpágina petista). Consideramos na análise a expressão da concordância passiva com as publicações, substantiva, por sinal, por meio do recurso apresentado pelos usuários à opção "Curtir". No entanto, a análise dos comentários, isto é, os registros de observações feitas pelos usuários - que se encontram no recurso técnico de interação do Facebook disponibilizado abaixo de cada publicação -, é extremamente relevante, no caso específico do estudo sobre os partidos políticos, por duas razões: em primeiro lugar, permite identificar o processo de acolhimento e de circularidade das opiniões entre os usuários e o centro original emissor da mensagem, ou seja, o partido. Em segundo lugar, favorece observar a utilização das webmídias como ferramentas técnicas propícias a um exercício politizado de crítica, de monitoramento e de fiscalização, sobremaneira por parte dos usuários que não se enquadram na categoria dos adeptos ao partido. Tomando por referência exclusiva a análise dos comentários dos usuários da página do PT no Facebook, encontramos os seguintes números porcentuais apresentados pelo Gráfico 2, discriminados por padrões de comentários: ${ }^{10}$

Gráfico 2 - PT e seus usuários nos comentários das postagens (números percentuais no período de 01/06/2013 a 30/06/2013)

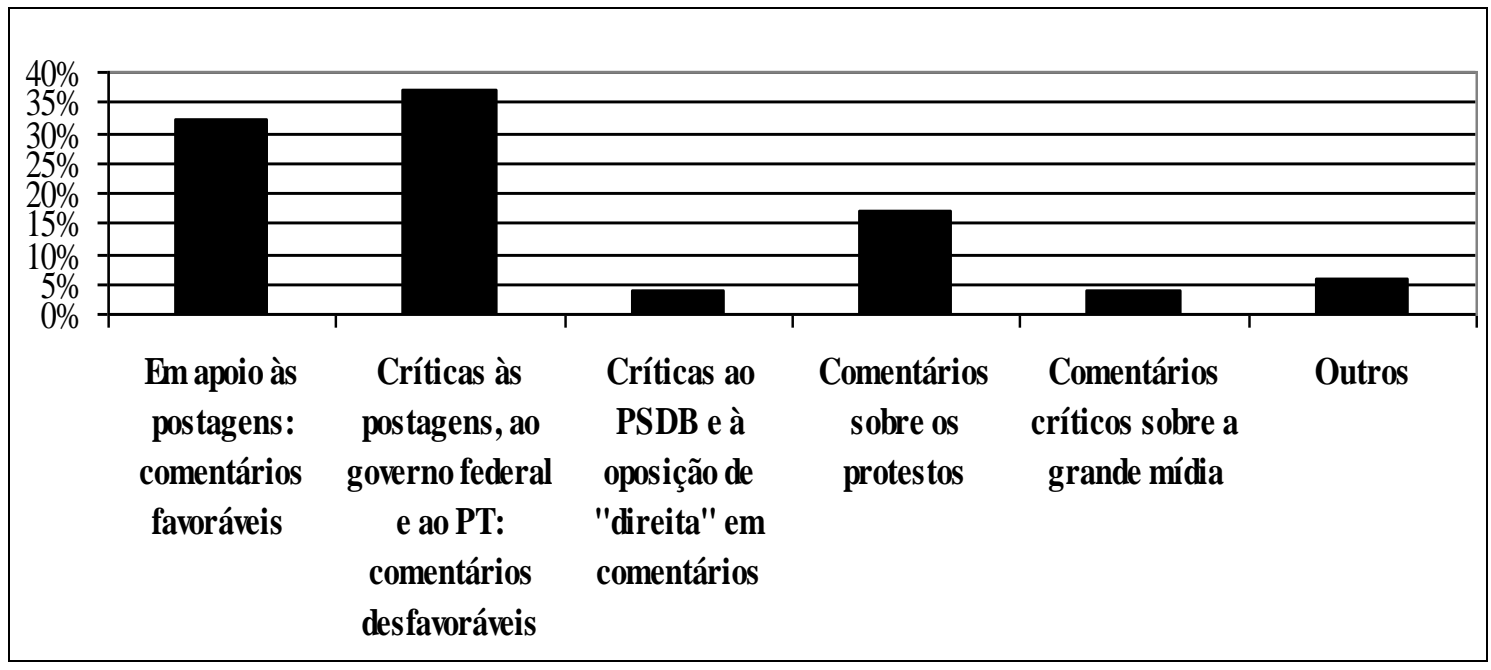

${ }^{10}$ Em números absolutos o total selecionado de comentários, para o Gráfico 2, alcançou 443 registros dos usuários.

Comunicação \& Informação, v. 16, n. 2, p. 53-71, jul./dez. 2013 
Fonte: Facebook

A tônica dos comentários não necessariamente circunscreve-se com precisão em cada registro feito por um usuário. Naturalmente, é usual que diferentes temas apareçam entrecruzados em um comentário feito pelo internauta. O exercício aqui empreendido foi de separação dos temas abordados por incidência de registro. Importante ainda ponderar que a frequência de comentários curtos produzidos pelos usuários também propiciou dificuldades à análise, seguramente fazendo escapar aspectos não contemplados e incompreensíveis no contexto estrito da postagem. É esse precisamente o caso do padrão outros que dispusemos no Gráfico 2, beirando a casa dos $6 \%$ de incidências. Acompanhando aos números identificados nas postagens do PT, também entre os usuários vemos uma baixa frequência de críticas destinadas ao PSDB e à oposição de "direita" (4\%). Um esquema de percepção peculiar, em que a auto-referencialidade petista tendeu a orientar a atenção sobre os negócios públicos e os fenômenos políticos. Os mesmos traços de circularidade e de reciprocidade de ideias entre partido e usuários podem ser observados no tema críticas à grande mídia: apenas $4 \%$ dos comentários analisados, em absoluta sintonia com as postagens emitidas pelo partido. É legítimo frisar que a maioria dos usuários da página do PT revelou o mesmo padrão acomodatício apresentado pelo partido, no que respeita aos meios massivos de comunicação. Demonstrações favoráveis e explícitas de concordância com as notícias veiculadas pela webmídia giraram em torno de $32 \%$ dos comentários. Não obstante, $37 \%$ dos comentários correspondiam a críticas às postagens, ao governo federal e ao PT, isoladamente a mais alta incidência comportamental dos usuários comentaristas. Esse número tendia a constituir um porcentual substantivo de não aderentes do partido, que utilizaram a página para tecer críticas e desempenhar um questionamento sobre as ideias e as propostas do PT e do governo federal.

Estritamente no que concerne aos comentários sobre os protestos eles atingiram $17 \%$ das preocupações dos usuários, no mês de junho. As manifestações de rua, na visão dos usuários, estão divididas em dois intervalos de tempo no mês de junho, com seus respectivos números absolutos e porcentuais. Demonstrando expressivo número de comentários após o dia 17/06, com 75 incidências (97\% do total), em contraste às duas (2) identificadas até o dia 16/06, ou seja 3\%, não é desrazoável ponderar uma estreita correlação temporal entre as postagens do partido e os comentários feitos pelos usuários. Durante o período em que imperou o silêncio na webpágina do PT e em que o universo dos 
manifestantes era classificado como "baderneiro" pelos meios massivos de comunicação, escassa incidência teve tal fenômeno nos comentários. Estes se concentraram na segunda metade do mês (17/06/2013 a 30/06/2013). Por outro lado, acerca do perfil dos comentários tecidos pelos usuários, em relação às manifestações propriamente ditas, temos os números porcentuais de opiniões refletidos no Gráfico 3.

Gráfico 3 - Os comentários dos usuários sobre as manifestações na página do PT (01/06/2013 a $30 / 06 / 2013)$

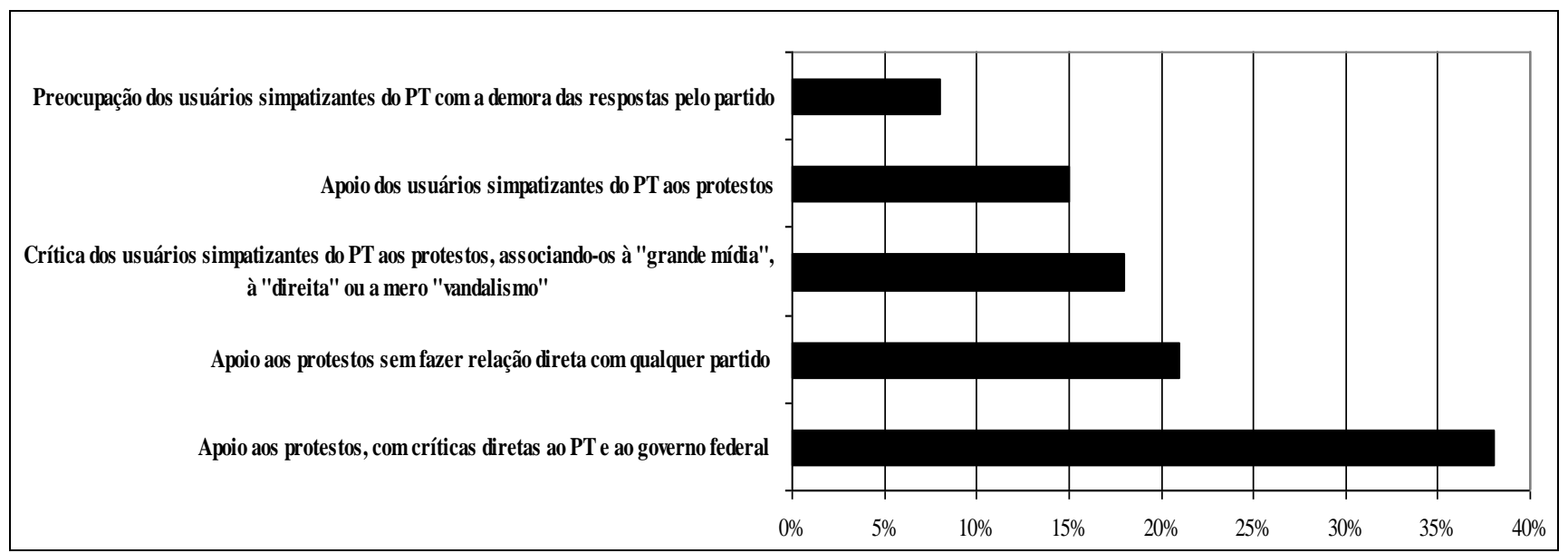

Fonte: Facebook

Em se tratando exclusivamente do tema não é difícil observar que grossa parte dos comentários tendeu a se manifestar de forma crítica às postagens e ao próprio partido. A incidência apoio aos protestos, com críticas diretas a PT e ao governo federal alcançou 38\% dos registros relacionados a esse tema nos comentários. Se somarmos aos $21 \%$ que também apoiavam aos protestos, mas que não faziam uma referência explícita a qualquer partido - não raro, referindo-se a todo o sistema partidário e à classe política em seu conjunto -, temos um total de 59\% de comentários referentes ao assunto, que tenderam a questionar a própria legitimidade do partido em tecer considerações sobre as manifestações de rua. Possibilidade de tratarem-se, primordialmente, de não aderentes ao partido. A expressão de revolta era reverberada, como se vê em comentário realizado em resposta a uma postagem, que apresentava o apoio petista ao Movimento Passe Livre, em 17 de junho: "Não acredito que estou lendo este enunciado... O Movimento é livre”, afirmava um usuário. Em resposta à postagem de 25/06 sobre a convocação do plebiscito pela presidente da República questionava outro usuário: "Impressionante 
como o PT consegue se apropriar de tudo como sendo ideia deles... A Dilma (...) foi forçada a se mexer, pelas multidões nas ruas... Multidões que vocês petistas estavam a criticar até ontem! Blá blá blá” (sic).

Concernente aos usuários que demonstravam adesão ao partido eles conformaram segmento minoritário de comentaristas dos protestos, alcançando, em conjunto, o porcentual de $41 \%$. As manifestações desses usuários foram heterogêneas e ficaram divididas. Alguns expressaram incômodos em relação ao que entendiam configurar uma demora nas respostas do partido (8\%) e demais (15\%) posicionaram-se favoravelmente às manifestações, salientando a sua legitimidade. É o caso de usuário que assim se expressou em postagem veiculada pela webpágina, em 17/06:

A maioria do povo está indignada com a situação em que se encontra. Realmente o Governo tem que se aproximar mais da população e solucionar os problemas (...). Por parte do prefeito Haddad está trabalhando (sic) para minimizar os impactos que afligem aos trabalhadores que dependem do transporte coletivo (...). O PT lutou e conquistou o poder (...), mas precisa criar mais alternativas, criar mais empregos para jovens, aproximar mais da população.

A incidência crítica dos usuários simpatizantes do PT aos protestos atingiu o significativo porcentual de $18 \%$ dos comentários sobre a temática manifestações. Foi marcada por ponderações que alegavam a emergência de um movimento golpista e conservador, tendo o partido - especialmente a presidente Dilma - como alvo. Nesse sentido, respostas dos usuários a publicações veiculadas entre os dias 17 e 19/06 são bastante ilustrativas: "Cadê a mobilização para um ato pró-democracia? A direita fascista adotou o Movimento Passe Livre. Sugiro um ato no vale do Anhangabaú para contrapor a esse pessoal!". Segundo outro usuário: "Acabamos de ouvir que foram pagos para manifestarem. (...) Investigar é bom porque saberemos que não é movimento", independente, mas que tem "a participação de partidos". Estritamente sob a luz dessa recepção do usuário, diferentemente de outras modalidades interpretativas identificadas, não nos parece ter ocorrido uma reciprocidade entre o emissor das informações, a webpágina do PT, e esse grupo de usuários, por conta da inexistência de postagens do partido que veiculassem esse último padrão de interpretação das jornadas.

\section{Considerações finais}


Uma das evidências mais salientes sobre as jornadas de junho é que consistiram em um conjunto de ações e de demandas que repercutiu as limitações da democracia representativa brasileira. Os apelos, feitos pelos jovens, à participação cidadã ampliada nos processos decisórios sugerem a necessidade de aperfeiçoamento das instituições democrático-representativas, contemplando a criação, assim como o acionamento de princípio constitucional já previsto, de mecanismos de participação mais intensa no exercício do poder político. Em que pesem as ambiguidades das demandas e dos comportamentos refletidos nas ruas, talvez seja legítimo asseverar que as experiências cotidianas, autônomas, dos jovens nas webpáginas tendem a guardar a virtual capacidade de assegurar, como rotina política, a ocupação do espaço público. A capacidade autônoma de produção e de ressignificação das informações, a dilatação dos circuitos de deliberação e de comunicação, por intermédio das plataformas digitais, constitui prática recorrente nas experiências dos jovens ciberativistas. Com efeito, malgrado o sabor prognóstico das ponderações acima, uma atividade intelectual temerária e habitualmente passível de frustração, os fenômenos postos em relevo possuem um substantivo potencial politicamente inovador. No que compete exclusivamente ao estudo de caso, apoiando-nos em um recorte delimitado de análise, é plausível afirmar que o PT possui expressiva representatividade, no sentido em que a sua webpágina no Facebook demonstra elevado grau de circularidade de ideias e de esquemas de percepção do mundo. A relação de reciprocidade configurada nos comentários de substantiva parte dos usuários da página deixa claro tal fenômeno político. Em um certo sentido, a interlocução dos usuários da página do partido, na mídia social, deixa entrever uma ponderável legitimidade da legenda junto aos seus aderentes, enquanto porta-voz político representativo. Todavia, se posto em comparação aos preceitos políticos esposados pelos jovens ciberativistas durante as jornadas - que sinalizavam, em parte, para um horizonte político futuro -, é difícil deixar de acentuar que o PT e a maioria dos usuários da sua webpágina denotavam razoável distância da concepção democrática que norteou a juventude protagônica das jornadas. Sistematicamente, revelaram estranhamento e hesitação em face das mobilizações cidadãs nas ruas.

Artigo submetido em 25/11/2013 e aceito em 18/02/2014.

Comunicação \& Informação, v. 16, n. 2, p. 53-71, jul./dez. 2013 


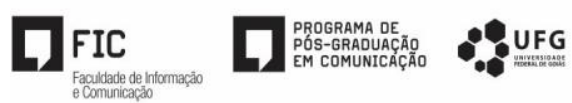

\section{Referências}

CARREIRO, R. O espaço local e o estudo dos ganhos democráticos via participação política online. Teoria \& pesquisa, São Carlos-SP, v. 21, n.2, p. 108-122, jul./dez. 2012.

CASTELLS, M. Comunicación y poder. Madri: Alianza Editorial, 2009.

CASTRO, M.C.P.S. Dilemas para a constituição do espaço público brasileiro: controvérsias midiáticas. In:___ MAIA, R. Mídia, esfera pública e identidades coletivas. Belo Horizonte: UFMG, 2006.

CHARAUDEAU, P. La argumentación persuasiva: el ejemplo del discurso político. In: SHIRO, M.; et al. Haciendo discurso: homenaje a Adriana Bolívar. Caracas: Universidad Central de Caracas, 2009.

CHARTIER, R. O mundo como representação. Estudos Avançados, Rio de Janeiro, v. 5, n. 11, p. 173-191, jan./abr. 1991.

CERTEAU, M. A invenção do cotidiano: artes de fazer. 16. ed. Petrópolis: Vozes, 2009.

DAIBERT, P.; FERREIRA, J. ¿Dónde estás? En búsqueda de lo tercero en el terreno de índices e íconos en el estudio de un conflicto inexplorado: el caso sharek.al jazzera.com. In: CARLÓN, M.; NETO, A. F. Las políticas de los internautas: nuevas formas de participación. Buenos Aires: La Crujía, 2012.

DUVERGER, M. Os partidos políticos. Rio de Janeiro: Zahar, 1970.

FACEBOOK Geraldo Alckmin. Disponível em: <https://www.facebook.com/geraldoalckmin>. Acesso em: 15 ago. 2013.

FACEBOOK Lula. Disponível em: <https://www.facebook.com/Lula>. Acesso em: 15 ago. 2013.

FACEBOOK Marcelo Freixo. Disponível em: <https://www.facebook.com/mfreixo>. Acesso em: 15 ago. 2013.

FACEBOOK PSDB. Disponível em: <https://www.facebook.com/Rede45?fref=ts>. Acesso em: 8 ago. 2013.

FACEBOOK PSOL. Disponível em: <https://www.facebook.com/pages/PSOL-Partido-Socialismo-eLiberdade/139591896063648?fref=ts>. Acesso em: 8 ago. 2013.

FACEBOOK PT. Disponível em: <https://www.facebook.com/pt.brasil?fref=ts>. Acesso em: 8 ago. 2013.

Comunicação \& Informação, v. 16, n. 2, p. 53-71, jul./dez. 2013 
FERREIRA, J. Trabalhadores do Brasil: o imaginário popular. Rio de Janeiro: FGV, 1997.

FONSECA, C. O povo unido avança sem partidos: dilemas atuais do sistema político chileno. Política Externa, São Paulo, v. 20, n. 3, p. 159-172, dez./fev. 2011-2012.

KANG, J. A mídia e a crise da democracia: repensando a política estética. Novos Estudos, São Paulo, v. 32, n. 93, p. 61-79, jul. 2012.

LEFEBVRE, R. Les primaires socialistes: la fin du parti militant. Paris: Raisons D’Agir, 2011.

LIMA, V. A. Mídia, rebeldia urbana e crise de representação. In: HARVEY, D.; et al. Cidades rebeldes. São Paulo: Boitempo; Carta Maior, 2013.

MHENNI, L.B. La revolución de la dignidad. Barcelona: Destino, 2011.

MOVIMENTO PASSE LIVRE. Não começou em Salvador, não vai terminar em São Paulo. In: HARVEY, D.; et al. Cidades rebeldes. São Paulo: Boitempo; Carta Maior, 2013.

NOGUEIRA, M.A. Em defesa da política. São Paulo: Senac, 2004.

SECCO, L. As jornadas de junho. In: HARVEY, D.; et al. Cidades rebeldes. São Paulo: Boitempo; Carta Maior, 2013.

SLIMIVICH, A. El facebook de los gobernantes: el caso de Cristina Fernández de Kirchner y de Mauricio Macri. In: CARLÓN, M.; NETO, A. F. Las políticas de los internautas: nuevas formas de participación. Buenos Aires: La Crujía, 2012.

SILVA, R. B. O PTB (1945-1964): suas tendências políticas internas e a hegemonia do diretório sulriograndense. Perseu: história, memória e política, São Paulo, v. 5, n. 7, p. 175-198, nov. 2011.

SILVA, T. T. Imagens da primavera árabe: estética, política e mídias digitais. Galáxia, São Paulo, n. 23, p. 35-47, jun. 2012.

SIMONDON, G. El modo de existência de los objectos técnicos. Buenos Aires: Prometeo Libros, 2007.

TORET, J. Um olhar tecnopolítico sobre os primeiros dias do \#15M. In: COCCO, G.; ALBAGLI, S. Revolução 2.0 e a crise do capitalismo global. Rio de Janeiro: Garamond, 2012.

ZIZEK, S. O violento silêncio de um novo começo. In: HARVEY, D.; et al. Occupy: movimentos de protesto que tomaram as ruas. São Paulo: Boitempo; Carta Maior, 2012.

Comunicação \& Informação, v. 16, n. 2, p. 53-71, jul./dez. 2013 